\title{
Reduction of redundant stimulus information in short-term memory*
}

\section{-ROBERT E. MORIN†, DOROTHY S. KONICK and KENNETH L. HOVING \\ Kent State University, Kent, Ohio 44240}

Twenty-six Ss were tested on a recognition memory task in which stimulus material was presented repetitiously on some trials. The number of items and the number of repeated itmes presented for memory were varied. A typical linear function relating reaction time of the recognition response to number of items in memory was found for nonredundant information. Evidence for the reduction of redundant information was provided by the finding that reaction times were alike on trials in which the amount of information remained constant although the number of items increased.

The $S$ who is presented a sequence of stimulus elements, like $\mathrm{AAB}$, will have little difficulty repeating the series. If, instead of recall, the task is one of recognizing single elements from the series, the $S$ with $\mathrm{AAB}$ in memory remembers more than he needs to know. A knowledge of two As in the series is not necessary to correctly recognize an $\mathbf{A}$ when it is presented as a recognition probe after the series. Rather, memory load could be reduced by transforming the set $\mathrm{AAB}$ into a smaller set with the structure $\mathrm{AB}$. If recognition reaction time is dependent on the number of items in memory at the time of the probe (Sternberg, 1966), will a $S$ given the above sequence respond as though he has two or three items in memory? The purpose of the present investigation was to determine the the ability of adults to perform the operation of reducing redundant information in a short-term recognition memory task.

\section{METHOD}

\section{Subjects}

The Ss were 26 male undergraduate college students enrolled in an introductory psychology class. Participation in the experiment fulfilled a course requirement. All Ss were tested individually in two successive sessions.

\section{Stimuli and Trials}

The stimuli were the digits 1 through 8 and a blank stimulus field. Each trial consisted of a memory set of two, three, or four sequentially presented stimuli followed by a ready signal and then a probe digit. The S's task was to respond positively if the probe was a digit in the memory set and negatively if it was not. On some trials, a digit in the memory set was repeated one or two times. As a temporal control for this condition, on other trials the repeated digits were replaced with a blank stimulus field. Thus, the memory set on any given trial was defined by the variable: total number of stimuli in the memory set $(2,3$, or 4$)$, number of repeated digits in the memory set $(0,1$, or 2$)$, and

*This study was supported by the U.S. Public Health Service National Institute of Child Health and Human Development, Grant HD-02086.

tNow at the State University of Northern Iowa. number of blank stimuli in the memory set $(0,1$, or 2$)$. Ten trial types were generated by combining levels of the three variables as presented in Table 1. For a given trial type, the positions of the blank or repeated items in the memory set were balanced across trials.

Each $S$ received a total of 720 trials in 18 blocks of 40 trials. Within each block there were four trials exemplifying each of the 10 basic types (Table 1). Two of these were positive and two were negative. Trials were arranged randomly within blocks. Serial positions within each trial type were probed equally often across blocks of trials. For trial types involving repeated digits, probes of nonrepeated digits were as probable as probes of repeated digits.

\section{Apparatus}

Testing was conducted in a sound-deadened room, where $S$

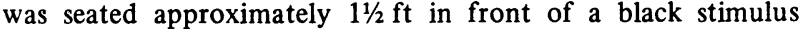
display panel located at eye level. Three adjacent rear-projection display cells were centerd on the panel. The left cell projected the memory set stimuli, and the right cell projected the probe stimuli. Digits were approximately 1 in. in height on a green background, and the blank stimulus was a green field approximately $1 \frac{1 / 4}{4} \times 1 \frac{1}{4}$ in. The center cell projected the word "ready" in white letters on a black background. Stimulus sequences were programmed on punched tape, and stimulus intervals were controlled by Hunter timers. The exposure set stimuli and the subsequent ready signal were each presented for $.45 \mathrm{sec}$ with a 10 -sec interval between presentations. Onset of the probe stimulus occurred $.10 \mathrm{sec}$ following termination of the ready signal. Probe onset activated a Hewlett-Packard counter, which recorded reaction time to the nearest $.01 \mathrm{sec}$. A vocal response by $S$ triggered a Hunter voice key which simultaneously stopped the counter, terminated the probe stimulus, and started the stimulus programmer. The RTs were printed on paper tape by a Hewlett-Packard digital recorder. The intertrial interval was $1 \mathrm{sec}$, in which time E recorded S's verbal response. A ready signal preceded each block of (40) trials; a vocal response by S terminated the ready signal and started the stimulus programmer.

\section{Procedure}

The $S$ was seated in the testing room. In the first session, verbal instructions were played to $S$ from a tape recorder with $E$ present. The $S$ was given 10 practice trials. The $E$ left the chamber, the 9 blocks of test trials were presented. A brief pause

Table 1

Types of Trials Generated by Combining Levels of Three Variables*

\begin{tabular}{cccc}
\hline $\begin{array}{c}\text { Number of } \\
\text { Stimuli } \\
\text { to be } \\
\text { Remembered }\end{array}$ & 2 & Number of Stimuli Presented \\
\cline { 2 - 4 } & 2 & 3 & 4 \\
\hline & $\mathrm{AB}$ & $-\mathrm{AB}$ & $--\mathrm{AB}$ \\
& & $\mathrm{AAB}$ & $\mathrm{AAAB}$ \\
3 & & $\mathrm{ABC}$ & $-\mathrm{ABC}$ \\
4 & & & $\mathrm{AABC}$ \\
& & & $\mathrm{ABCD}$ \\
\hline
\end{tabular}

*Trial types are arranged by number of stimuli presented and number of stimuli to be remembered. $A$ "-" indicates a blank field. 


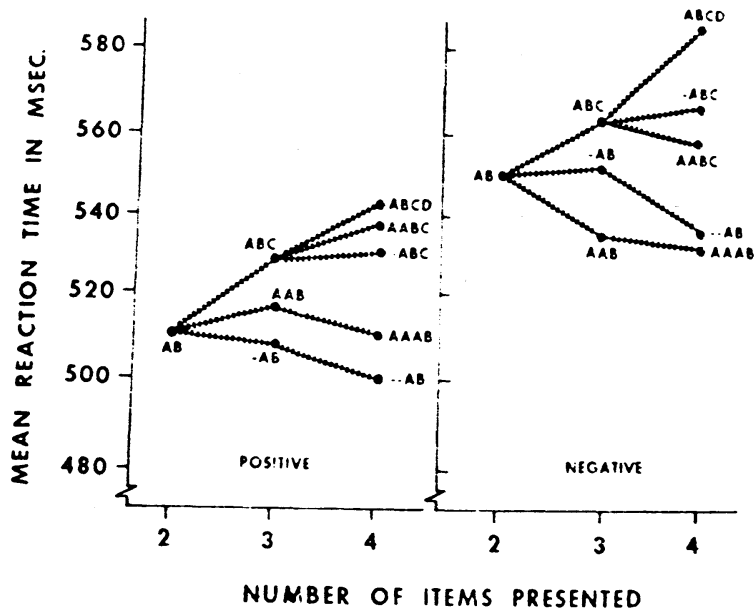

Fig. 1. RT on nonrepeated positive and negative trials as a function of number of items presented.

followed each block of trials while $E$ changed the stimulus programming tape. In the second session, 10 practice trials and the remaining 9 blocks of test trials were presented. Each S received the 18 blocks in a different random order. A rest period of approximately $5 \mathrm{~min}$ followed the 5 th block of trials in each session. Testing time was approximately $40 \mathrm{~min}$ per session.

\section{RESULTS AND DISCUSSION}

Every S's mean correct reaction time (RT) was computed for positive and negative responses on each of the 10 trial types. Positive responses to nonrepeated items were calculated separately from responses to repeated items on trials involving repeated stimuli. The nonrepeated positive data and the negative data are presented in Fig. 1, where RTs are plotted as a function of the total number of stimuli in the memory set. Nine points are plotted on each graph, 1 for each of the 10 trial types except type AABB, which has no nonrepeated items.

Figure 1 shows that reaction time increases as a function of the number of items in the memory set in linear fashion. This function is defined on both positive and negative graphs by the points $\mathrm{AB}, \mathrm{ABC}$, and $\mathrm{ABCD}$. Results of analyses of variance showed that the linear components of the positive and negative functions are significant $(F=41.9, \mathrm{df}=1 / 25, \mathrm{p}<.01$, and $\mathrm{F}=30.0$, $\mathrm{df}=1 / 25, \mathrm{p}<.01$, respectively) and that no difference between the two slopes exists $(F=3.6, d f=1 / 25$, $p>.05)$. The average slope of the functions is approximately $20 \mathrm{msec}$ per item, a rate somewhat faster than is typically observed (Sternberg, 1963, 1966).

More important, the data of Fig. 1 indicate that Ss can and do reduce redundant information in the memory task. It can be seen in Fig. 1 that the functions defined by the points $\mathrm{AB}, \mathrm{AAB}, \mathrm{AAAB}$, are not linearly increasing functions despite the fact that the number of items increases from two to four. Instead, the $A B, A A B$, $\mathrm{AAAB}$ functions for positive responses is noticeably flat, with no significant slope $(F<1)$. Furthermore, the $A B$, $\mathrm{AAB}, \mathrm{AAAB}$ functions for negative responses displays a significantly linear decrease in $R T(F=15.9, \mathrm{df}=1 / 25$, $p<.01)$. Findings for the temporal control condition, which is defined by points $A B,-A B,--A B$, are similar. Apparent again is the curious decrease in RT as the number of items in the memory sets increase; both positive and negative functions had significant linear components $(\mathrm{F}=14.2, \mathrm{df}=1 / 25, \mathrm{p}<.01, \mathrm{~F}=4.8$, $\mathrm{df}=1 / 25, \mathrm{p}<.05$, respectively). The tendency toward decreasing RTs suggests that Ss may have used the additional time afforded by a blank stimulus field or by a redundant stimulus to rehearse material.

The reduction of redundant information is also apparent when the variable of number of items to be remembered is considered. Table 1 shows that there -were six basic trial types which required only two items be remembered, three types that required memory for three items, and one type (ABCD) that necessitated storage of four stimuli. It can be observed in Fig. 1 that, without exception, mean RTs are greater for trial types for which more items must be remembered. Considering first the positive responses, longest times were observed for $A B C D$, next longest for $A B C, A A B C$, and $-A B C$, and shortest for the remaining five trial types (Type AABB is excluded). Pairwise comparisons among these three groups of trials were tested with an analysis of variance. The time required to respond when the to-be-remembered set consisted of four stimuli (ABCD) was significantly longer than when it consisted of three $(\mathrm{ABC}, \mathrm{AABC}$, and $-\mathrm{ABC}) \quad(\mathrm{F}=9.1, \quad \mathrm{df}=1 / 25$ $\mathrm{p}<.01$ ), which, in turn, was significantly longer than when the set consisted of two stimuli $(\mathrm{F}=46.6$, $\mathrm{df}=1 / 25, \mathrm{p}<.01)$. An identical pattern is observed in Fig. 1 for negative responses. Statistical results for the pairwise comparisons were $F=19.5, \mathrm{df}=1 / 25, \mathrm{p}<.01$, and $F=36.8, \mathrm{df}=1 / 25, \mathrm{p}<.01$, respectively. Not only does reduction occur, but the data suggest that it may be complete rather than partial. Trial types, which are alike with respect to the number of items to be remembered, show similar RTs.

Although reactions to probes of nonrepeated items are central to the purpose of the present investigation, responses to probes of repeated stimuli are also of interest. For Trial Types $\mathrm{AAB}, \mathrm{AABC}$, and $\mathrm{AAAB}$, reactions to repeated stimuli were from 15 to $25 \mathrm{msec}$ faster than they were to nonrepeated elements $(F=10.8, d f=1 / 25, p<.01)$. Despite the fact that $\mathrm{Ss}$ reduce redundant information, the finding is that Ss responded differentially to the redundant information. Apparently more than a simple reduction operation is involved. The results suggest that $\mathrm{Ss}$ can perform a transformation of the material which retains the feature of redundancy but which allows the material to be treated efficiently in short-term recognition memory.

\section{REFERENCES}

Sternberg, S. Retrieval from recent memory: Some reaction-time experiments and a search theory. Paper read at Fourth Annual Meeting of the Fsychonomic Society, 1963.

Sternberg, S. High speed scanning in human memory. Science, $1966,153,652-654$.

(Received for publication April 15, 1973.) 